\title{
In vitro assay for the quantitation of apoptosis-induced alterations of nuclear envelope permeability
}

\author{
Patricia Grote \& Elisa Ferrando-May
}

Department of Biology, University of Konstanz, Universitaetsstrasse 10, D-78464 Konstanz, Germany. Correspondence should be addressed to E.F.M. (elisa.may@uni-konstanz.de).

This protocol describes how to perform comparative measurements of the permeability of the nuclear envelope in adherent cells. The plasma membrane is permeabilized at low digitonin concentrations, leaving the nuclear membrane intact. These semi-permeabilized cells are incubated with cytosolic extracts prepared in advance and with a fluorescent reporter molecule whose molecular weight exceeds the size-exclusion limit of the nuclear envelope. Images are taken with a confocal microscope and subsequently analyzed using a custom-made software program that recognizes the nuclei automatically and calculates the mean nuclear fluorescence signal. Here, we measure the increase in nuclear permeability triggered by cytosolic extracts from cells dying by apoptosis. This method can be employed for the study of processes that affect the nucleocytoplasmic distribution of fluorescent molecules in cell populations. The large size of the samples means that subtle fluctuations in nuclear fluorescence can be detected with a high confidence level. Isolation of cell extracts takes 5-6 h, and the preparation and imaging of 15 or so specimens takes $4-5 h$.

\section{INTRODUCTION}

The nuclear envelope of eukaryotic cells controls macromolecular exchange between the nucleus and the cytoplasm. Molecules traverse the envelope through nuclear pore complexes (NPCs) either by facilitated, energy dependent transport or by passive diffusion. The latter is restricted to molecules smaller than $2540 \mathrm{kDa}^{1,2}$. Both the maintenance of this permeability barrier and regulated passage across it are essential for cell survival. In fact, cellular stress resulting from exposure to toxins or pathogens has been shown to compro mise the integrity of the NPC and to alter the nucleocytoplasmic distribution of several molecules ${ }^{3-7}$. On the other hand, nuclear transport and permeability also respond to physiological changes in the cell's metabolic activity, e.g., after growth factor stimulation ${ }^{8-10}$. Overall, studies suggest that the nucleocytoplasmic barrier responds very sensitively to changes of the cellular environment. Here, we describe a method to monitor alterations in the permeability of the nuclear envelope for freely diffusible molecules.

Outline of the method

This protocol describes how to measure relative changes in the size exclusion limit of the nuclear envelope in semi permeabilized cells. It is based on a procedure originally established by Adam et al. ${ }^{11}$ and widely employed for studies concerning nucleocytoplasmic trans port (see, e.g., refs. 12,13). The plasma membrane is selectively permeabilized at low concentrations of digitonin, leaving the nuclear membrane intact. The resulting semi permeabilized cells are then supplemented with cellular extracts prepared in advance. In this reconstituted system, the molecular passage across the nuclear membrane can be examined under native conditions. To investigate changes in the size exclusion limit of the nuclear pore, a fluorophore of known molecular weight is added to the extracts (Fig. 1). In our hands, $70 \mathrm{kDa}$ Texas Red labeled dextran has performed very well. It penetrates rapidly through the permeabilized plasma membrane and distributes homogeneously into the cytoplasm. Confocal images of these specimens show the nuclei as dark holes surrounded by bright cytoplasm (see Step 31). This distribution pattern is obtained when the extracts are derived from a healthy, proliferating cell population. Complete nuclear exclusion of $70 \mathrm{kDa}$ dextran is also observed in microinjected cells ${ }^{14}$. Under conditions that compro mise the barrier properties of the nuclear envelope, the dextran permeates to a variable extent into the nucleus. This results in an increase of the nuclear fluorescence signal. The average signal intensity of all nuclei in a given image is measured using a customized image analysis program called NPA (Nuclear Perme ability Assay $)^{15}$. The software is a pattern recognition algorithm that identifies all in focus nuclei according to a set of user defined parameters. Several images from nonoverlapping fields of the speci men are recorded, and at least three specimens are analyzed for each experimental condition to be tested. The results are then compared in a two tailed paired $t$ test using common statistics programs.

\section{Advantages and limitations}

There are two main alternative methods to the semi permeabilized cell system for the measurement of nuclear permeability. Both employ live cells. The first involves the microinjection of fluorescent

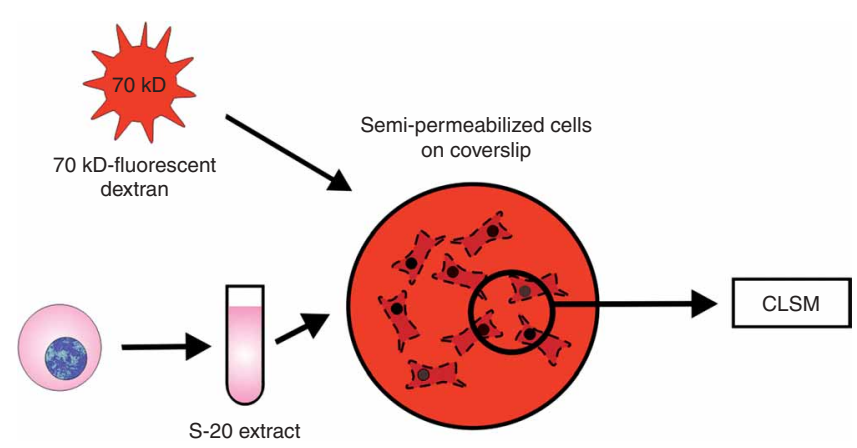

Figure 1 | Overview of the assay. 
permeability reporters; the second, the transfection and expression of corresponding DNA constructs. Whereas microinjection requires expertise and is easiest to perform with large cells such as oocytes, the major limitation of the second approach is the unpredictable nucleocytoplasmic distribution of proteins when compared to dextrans. Dextrans are inert and perfectly soluble in an aqueous environment, and their molecular diameter increases proportionally to their molecular weight (see ref. 16 and literature cited therein). In contrast, the shape and effective size of fluorescent proteins are strongly influenced by their aa composition and the resulting tertiary structure. In addition, they may aggregate at high expression levels and/or interact with cellular structures. Therefore their nucleocyto plasmic distribution pattern does not necessarily reflect the size exclusion limit of the NPC. Tri and tetrameric fusions of GFP or GFP analogs of $80100 \mathrm{kDa}$ molecular weight can still penetrate into the nucleus of healthy cells (P.G. and E.F. M., unpublished data).

In semi permeabilized cells, the nuclear envelope resides in its native environment, similarly to live intact cells, but is freely accessible to exogenous substances. The method is thus of advan tage for studying the effects of compounds with low or unknown membrane penetration. As pointed out, the state of the nucleo cytoplasmic barrier is a reliable indicator of changes in the cell's physiology. Using our method, nuclear envelope permeability could be employed as an endpoint for the toxicity of chemical substances. Similarly, the effect of pharmacological inhibitors could be evaluated more directly than in whole cells.
The availability of automatic image analysis software allows us to score a large number of nuclei. Therefore the protocol provides a population assay to quantify nuclear permeability changes. The results obtained can be correlated with those of common biochemical assays, such as immunoblots and enzyme activity measurements.

We have exploited this system to study alterations of nuclear permeability associated with apoptotic cell death. To this end, we have isolated S 20 extracts from cells treated with different apoptosis inducers. The method can be used with any kind of cellular extract or subcellular fraction. It is not restricted to HeLa cells, but flat, well adhering cells give the best results. R6 rat fibroblasts and SW480 human colon carcinoma cells worked well in our hands (see ANTICIPATED RESULTS). In terms of optimal object recognition, the evaluation software NPA, freely downloadable at http://edukon. biologie.uni konstanz.de/download.html, offers the possibility to adapt the parameters that control the threshold of nuclear fluores cence, the density and the shape of the objects. However, two basic conditions have to be fulfilled: first, the intensity of the nuclei should be low compared with that of the surrounding cytoplasm and image background; second, the intensity distribution within the nucleoplasm should be homogeneous. To analyze images where the signal intensity in the nucleoplasm is higher than in the background (e.g., in nuclear import reactions), the grayscale needs to be inverted. NPA is not suited to the quantitation of nuclear speckles.

\section{MATERIALS}

\section{REAGENTS}

- $70 \mathrm{kDa}$ Texas Red labeled dextran (Molecular Probes, cat. no. D 1830)

- ATP (Sigma, cat. no. A 3377)

- $\alpha$ CD95 antibody clone CH11 (Upstate, cat. no. 05 201)

- Creatine phosphokinase (Sigma, cat. no. C 3755)

- D glucose (Sigma, cat. no. D 8375)

- Digitonin (Fluka, cat. no. 37006)

- EGTA (Sigma, cat. no. E 4378)

- GTP (Fermentas, cat. no. R0161)

- HEPES (Roth, cat. no. 9195.3)

- KOAc (Merck, cat. no. 1.04820.1000)

- KOH (Merck, cat. no. 1.05033.1000)

- $\mathrm{Mg}(\mathrm{OAc})_{2}$ (Sigma, cat. no. M 5661)

- Phosphocreatine (Sigma, cat. no. P 6502)

- Saccharose (Merck, cat. no. 1.07654.1000)

- Stopcock grease (Merck, cat. no. 4318.0250)

- PMSF (Sigma, cat. no. P 7626)

- Leupeptin (Sigma, cat. no. L 2023)

- Pepstatin A (Sigma, cat. no. P 4265)

- Aprotinin (Sigma, cat. no. A 1153)

-DTT (Sigma, cat. no. D 9779)

- Trypan blue (Sigma, cat. no. T8154)

- Hoechst 33342 (Molecular Probes, cat. no. H1399)

- BCA Protein Assay Kit (Pierce)

- Fluorimetric Caspase Assay (Roche Applied Science, cat. no. 03005372001)

EQUIPMENT

- $16 \mathrm{~mm}$ glass coverslips (Menzel Glaser, no. 1)

- $\varnothing 10 \mathrm{~cm}$ dishes (Corning, cat. no. 430167)

- 12 well plates (Corning, cat. no. 3513)

- 6 well plates (Corning, cat. no. 3506)

- Cell culture media (DMEM, GIBCO, cat. no., 41966 029; RPMI1640,

GIBCO, cat. no., 21875 034)

- Routine epifluorescence microscope (e.g., Zeiss Axiovert 40)

- Coverslip holder, custom made, aluminum (Fig. 2)

- Tweezers (Roth, cat. no. K343.1)
- Magnetic stir bar (round, $1.52 \mathrm{~cm}$ )

- Q Tips

- Ceramic cover glass staining rack (Thomas Scientific, cat. no. 8542E40)

- Wet chamber (see EQUIPMENT SETUP)

- Confocal laser scanning microscope (e.g., Zeiss LSM510Meta)

- Evaluation software, Cutter NPA (freely downloadable at http://

edukon.biologie.uni konstanz.de/download.html)

REAGENT SETUP

Equilibration buffer (EB) $50 \mathrm{mM} \mathrm{HEPES/KOH} \mathrm{pH} \mathrm{7.5,} 500 \mathrm{mM} \mathrm{KOAc,}$ $50 \mathrm{mM} \mathrm{Mg}(\mathrm{OAc})_{2}$.

PBS $137 \mathrm{mM} \mathrm{NaCl}, 10 \mathrm{mM} \mathrm{Na} 2 \mathrm{HPO}_{4}, 3 \mathrm{mM} \mathrm{KH} \mathrm{PO}_{4} \mathrm{pH} 7.4$.

Cell Extraction Buffer (CEB) $50 \mathrm{mM} \mathrm{HEPES/KOH} \mathrm{pH} \mathrm{7.4,} 50 \mathrm{mM} \mathrm{KCl}$, $5 \mathrm{mM}$ EGTA, $2 \mathrm{mM} \mathrm{MgCl}$. Add $1 \mathrm{mM}$ DTT, $1 \mathrm{mM}$ PMSF, $100 \mu \mathrm{M}$ leupeptin, $100 \mu \mathrm{M}$ pepstatin $\mathrm{A}, 100 \mu \mathrm{M}$ aprotinin shortly before use.

Permeabilization buffer (PB) $20 \mathrm{mM} \mathrm{HEPES/KOH} \mathrm{pH} \mathrm{7.5,} 110 \mathrm{mM} \mathrm{KOAc}$ $5 \mathrm{mM} \mathrm{Mg}(\mathrm{OAc})_{2}, 0.5 \mathrm{mM}$ EGTA. Prepare a $10 \times$ stock solution, sterilize by filtration and store at $4{ }^{\circ} \mathrm{C}$; dilute to $1 \times$ and add $250 \mathrm{mM}$ saccharose immediately before use.

Transport buffer (TRB) $20 \mathrm{mM}$ HEPES, $110 \mathrm{mM} \mathrm{KOAc,} 2 \mathrm{mM} \mathrm{Mg}(\mathrm{OAc})_{2}$, $5 \mathrm{mM}$ NaOAc, $0.5 \mathrm{mM}$ EGTA; dissolve all components except EGTA, adjust to $\mathrm{pH} 7.3$ with $\mathrm{KOH}$, add EGTA. Prepare a $10 \times$ stock solution, sterilize by filtration and store at $4{ }^{\circ} \mathrm{C}$; dilute to $1 \times$ and add $250 \mathrm{mM}$ saccharose immediately before use.

E Mix $(20 \times$ stock) $10 \mathrm{mM}$ ATP, $10 \mathrm{mM}$ GTP, $250 \mathrm{mM}$ D glucose, $200 \mathrm{mM}$ phosphocreatine, $0.3 \mathrm{U} \mathrm{ml}^{-1}$ creatine phosphokinase, $20 \mathrm{mM} \mathrm{HEPES} / \mathrm{KOH} \mathrm{pH} \mathrm{7.3.}$ $70 \mathrm{kDa}$ Texas Red labeled dextran Dissolve in PBS to a final concentration of $20 \mathrm{mg} \mathrm{ml}^{-1}$, store at $-20^{\circ} \mathrm{C}$ in small $(20 \mu \mathrm{l})$ aliquots; prepare dextran solutions $\left(0.6 \mathrm{mg} \mathrm{ml}^{-1}\right)$ in TRB. $\triangle$ CRITICAL Do not freeze thaw.

Digitonin $20 \mathrm{mg} \mathrm{ml}^{-1}$ in water. Heat to $95{ }^{\circ} \mathrm{C}$ for $10 \mathrm{~min}$ with occasional vortexing. Cool down to room temperature (RT; $2023{ }^{\circ} \mathrm{C}$ ) and centrifuge for $5 \mathrm{~min}$ at RT at $20,000 \mathrm{~g}$ in a tabletop centrifuge. Transfer the supernatant to a fresh tube. Store in $2050 \mu$ aliquots at $-20{ }^{\circ} \mathrm{C}$.

$\mathrm{Dig} / \mathrm{PB}$ solution $24 \mu \mathrm{g} \mathrm{ml}^{-1}$ digitonin in $\mathrm{PB}$.

EQUIPMENT SETUP

Wet chamber Lay a piece of parafilm in a Petri dish, soak paper tissues with $\mathrm{H}_{2} \mathrm{O}$ and place them around the edge of the dish. 


\section{PROCEDURE}

\section{Preparation of S-20 extracts from CH11-treated Jurkat T-cells (clone E6-1)}

1) Grow Jurkat T-cells in suspension in five big cell culture flasks $\left(175 \mathrm{~cm}^{2}\right)$ starting with a density of $1 \times 10^{5} \mathrm{ml}^{-1}$ to approximately $4 \times 10^{5} \mathrm{ml}^{-1}$.

2| Harvest $4 \times 10^{8}$ cells, corresponding to approximately 1.25 I of exponentially growing culture, by centrifugation (5 min, 250g, RT).

3| Wash the cells with $50 \mathrm{ml}$ serum-free RPMI medium.

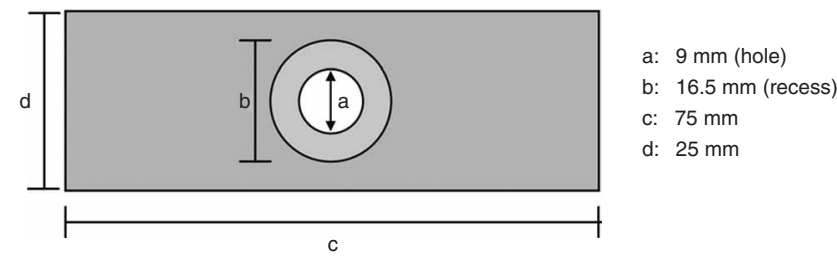

Figure 2 | Illustration of the coverslip holder. The holder is $1 \mathrm{~mm}$ thick, with a recess of $0.2 \mathrm{~mm}$ where the circle with the diameter $b$ is indicated. This enables a planar insertion of the coverslip. The recess is on both the upside and the downside of the holder such that one coverslip can be fixed on each side.

4| Resuspend the cells in $25 \mathrm{ml}$ serum-free RPMI medium (cell density approximately $1.6 \times 10^{7} \mathrm{ml}^{-1}$ ).

5| Distribute the cell suspension between two $10 \mathrm{~cm}$ Petri dishes $\left(12.5 \mathrm{ml}\right.$ each) and add $250 \mathrm{ng} \mathrm{ml}^{-1}$ of agonistic $\alpha$-CD95 antibody clone $\mathrm{CH} 11$. Incubate for $60-90 \mathrm{~min}$ in a cell culture incubator. Check for induction and progression of apoptosis at regular intervals by staining a small aliquot of the suspension with Hoechst $33342\left(500 \mathrm{ng} \mathrm{hl}^{-1}\right.$ ) and scoring for condensed nuclei under a fluorescence microscope.

6| When approximately $20 \%$ of the cells show an apopototic phenotype harvest the cells by centrifugation ( 5 min, $250 \mathrm{~g}$, $\left.4^{\circ} \mathrm{C}\right)$.

7| Wash the cells in $50 \mathrm{ml}$ ice-cold PBS supplemented with $1 \mathrm{mM} \mathrm{DTT,} 1 \mathrm{mM}$ PMSF, $100 \mu \mathrm{M}$ leupeptin, $100 \mu \mathrm{M}$ pepstatin A, $100 \mu \mathrm{M}$ aprotinin.

8| Wash the cells in $25 \mathrm{ml}$ CEB.

9| Resuspend the cells in $1 \mathrm{ml}$ CEB and transfer to a $1.5 \mathrm{ml}$ reaction tube.

10| Spin down the cells briefly in a tabletop centrifuge $\left(1 \mathrm{~min}, 20,000 \mathrm{~g}, 4^{\circ} \mathrm{C}\right)$ and aspirate the supernatant.

11 Resuspend the cells in a volume of CEB buffer equal to the packed cell pellet (approximately $400 \mu \mathrm{l}$ ).

12| Lyse the cells by holding the tube first in liquid nitrogen for 2 min and then transferring it immediately to a $37^{\circ} \mathrm{C}$ water bath until the suspension is thawed.

13| When you are performing this procedure for the first time, it is advisable to monitor cell lysis by trypan blue staining. Meanwhile keep the suspension on ice. Remove $2 \mu \mathrm{l}$ of the suspension and add $200 \mu \mathrm{l}$ of $0.04 \%$ trypan blue. Observe under a light microscope: lysed cells are permeable to trypan blue. Subject the cells to one or two freeze-thaw cycles until all the cells are lysed. Jurkat T-cells require only one cycle.

14| Centrifuge the lysed cell suspension $\left(20 \mathrm{~min}, 20,000 \mathrm{~g}, 4^{\circ} \mathrm{C}\right)$.

15 Transfer the supernatant to a fresh $1.5 \mathrm{ml}$ reaction tube and repeat the centrifugation until you get a clear supernatant (approximately two times).

16 Take a small aliquot to determine the total protein concentration using a conventional colorimetric assay. We use the BCA Protein Assay Kit. Snap-freeze the S-20 extract in aliquots corresponding to 150-300 $\mu \mathrm{g}$ of total protein and store them at $-80^{\circ} \mathrm{C}$.

$\triangle$ CRITICAL STEP Avoid refreezing the extracts once thawed.

17| As controls, isolate S-20 extracts from untreated Jurkat T-cells using the same procedure but skipping Steps 4-7. Snap-freeze the S-20 extract in aliquots corresponding to $150-300 \mu \mathrm{g}$ of total protein and store them at $-80{ }^{\circ} \mathrm{C}$.

PAUSE POINT The extracts can be stored for up to 3 months.

\section{Preparation of permeabilized cells to be incubated with cell extract (Steps 1-17)}

18 At 16-20 $\mathrm{h}$ before the start of the experiment, seed $1-1.3 \times 10^{5}$ exponentially growing cells in 12-well plates containing $\varnothing 16 \mathrm{~mm}$ glass coverslips.

$\triangle$ CRITICAL STEP Accurate seeding is required. The cells must be spread very evenly onto the coverslip to ensure uniform permeabilization of the culture. This can be achieved by gentle tapping on each side of the plate. Cell number and distribution should not vary from well to well. For the experiment the cells should be at $30-40 \%$ confluency. Try different concentrations to 
establish the optimal seeding density for your cells. Once the seeding density is optimized, keep the number of cells and time of growth constant.

$\triangle$ CRITICAL STEP All further steps are performed on ice unless indicated otherwise. Coverslips should never dry out.

? TROUBLESHOOTING

19| Transfer six coverslips to a ceramic rack that has been placed into a beaker containing $60 \mathrm{ml}$ cold PBS. Leave one position free between each coverslip. Incubate for $1 \mathrm{~min}$.

20| Transfer the rack into a beaker containing $60 \mathrm{ml}$ Dig/PB solution and a small magnetic stir bar. The bar should rotate at the slowest possible speed at the center of the beaker (place the ice box onto the magnetic stirrer). Incubate for 3-6 min. $\triangle$ CRITICAL STEP The optimal permeabilization conditions must be determined for each cell line and every time a new Dig/PB solution is prepared. Perform incubations with extracts from healthy, untreated cells according to Step 17. Try different times and digitonin concentrations. Choose the lowest digitonin concentration and the shortest incubation time that allows dextran passage through the plasma membrane. Keep these parameters constant and use one coverslip per batch of six to perform a control. Do not change Dig/PB within a series of experiments.

? TROUBLESHOOTING

21| Place the rack into a beaker containing $60 \mathrm{~mL} \mathrm{~PB}$ and using a tweezer transfer the coverslips into a 6-well plate containing $2 \mathrm{ml}$ PB per well. Incubate for $5 \mathrm{~min}$.

22 Aspirate the PB (one well at a time) and add fresh PB (2 $\mathrm{ml}$ per well). Incubate for $10 \mathrm{~min}$.

$\triangle$ CRITICAL STEP Be careful not to touch the surface of the coverslips while aspirating, do not let them dry out and avoid adding the fresh buffer directly onto the coverslips. This leads to detachment of the cells.

23| Aspirate the PB (one well at a time) and add TRB (2 ml per well). Incubate at least $5 \mathrm{~min}$.

$\triangle$ CRITICAL STEP The permeabilized cells are stable in TRB for approximately $90 \mathrm{~min}$.

? TROUBLESHOOTING

Specimen preparation

24| Thaw the S-20 extract on ice. Prepare the following reaction mix in a $1.5 \mathrm{ml}$ reaction tube:

\begin{tabular}{ll}
\hline Extract & Equivalent of $\mathbf{1 5 0 - 3 0 0} \boldsymbol{\mu g}$ total protein \\
\hline Equilibration buffer & $1 / 10$ volume of cytosol \\
$2.5 \mathrm{M}$ saccharose & $1 / 10$ volume of cytosol \\
$20 \times$ E-mix & $1.5 \mu \mathrm{l}$ \\
TRP & ad $30 \mu \mathrm{l}$ \\
\hline
\end{tabular}

Spin down the tube quickly and incubate for $2 \mathrm{~min}$ at RT.

25| Take a coverslip with permeabilized cells, carefully drain residual buffer on tissue paper and place it into a wet chamber.

26| Add the protein extract reaction mix onto the coverslip. Distribute it evenly by gently tilting the dish. Incubate for 7 min at RT.

$\triangle$ CRITICAL STEP Work quickly to avoid the coverslips drying out.

27| Add $10 \mu \mathrm{l}$ of a $0.6 \mathrm{mg} \mathrm{ml}^{-1}$ dextran solution onto the coverslip. Distribute it evenly by gently tilting the dish. Protect from light and incubate for $7 \mathrm{~min}$ at RT.

28| During the incubation period prepare a coverslip holder: using a Q-Tip apply a thin film of grease on both sides of the recess surrounding the hole of the holder. Gently press a clean $\varnothing 16 \mathrm{~mm}$ coverslip onto one side. Place the holder on this side onto a piece of parafilm and drop $100 \mu \mathrm{l}$ of dextran solution $\left(0.2 \mathrm{mg} \mathrm{ml}^{-1}\right)$ into the cavity. Store at RT in the dark until use.

29| Using the tweezers take the coverslip prepared in Step 27, tilt it above the cavity of the holder (as prepared in Step 28) and let the incubation solution drop into it. Then gently press the coverslip against the recess of the holder with the side carrying the cells facing the liquid-filled cavity. Carefully remove excess liquid with tissue paper, check that the chamber does not leak and image immediately.

\section{Image acquisition}

30| Images are acquired through a confocal microscope with a $\times 40$ oil-immersion objective lens. The z-position is chosen such that the majority of the nuclei are in focus, showing a sharp contour and a minimum of fluorescence. We have used a Zeiss 
LSM510 microscope equipped with a motorized $x y$-stage, which gives the option of automatically scanning different fields of the specimen. Several (e.g., five) randomly distributed nonoverlapping fields of the specimen are selected in the stage and focus control menu of the LSM510 software and an overview image of each position consisting of tiled partial images is recorded automatically (Fig. 3). Alternatively, fields may be selected manually; however, image recording from one specimen should not exceed 5 min. Image frame size should be $512 \times 512$ pixels. With our instrument, a $3 \times 3$ tile scan (resulting in nine images per stage position) gives a good compromise between acquisition time and image quality. The pinhole diameter is set to yield $1 \mu \mathrm{m}$ slices.

$\triangle$ CRITICAL STEP For statistical analysis, a minimum number of 12-15 images should be collected for each experiment. We usually prepare three coverslips for each condition to be tested.

\section{Image data analysis}

31 Image data are analyzed using the custom-made software NPA. You will be prompted to register to receive the password required for downloading the installation file. When installation is completed, open the folder "Cutter-NPA." Images need to be in TIFF, JPG or BMP format to be opened by NPA. The data format must be specified in the file NPA.ini in the "Cutter-NPA" folder. The folder contains two .exe files, Cutter.exe and NPA.exe. The latter starts the NPA evaluation software proper. Use this to analyze single images. If you have collected composite images with the Tile Scan option, use Cutter to open tiled images and decompose them into single images. You can start NPA directly from Cutter simply by clicking the Start button (see Fig. 4). Detailed instructions on how to use Cutter and NPA are provided with the installation file (UserManual.pdf). Depending on the type of cells and

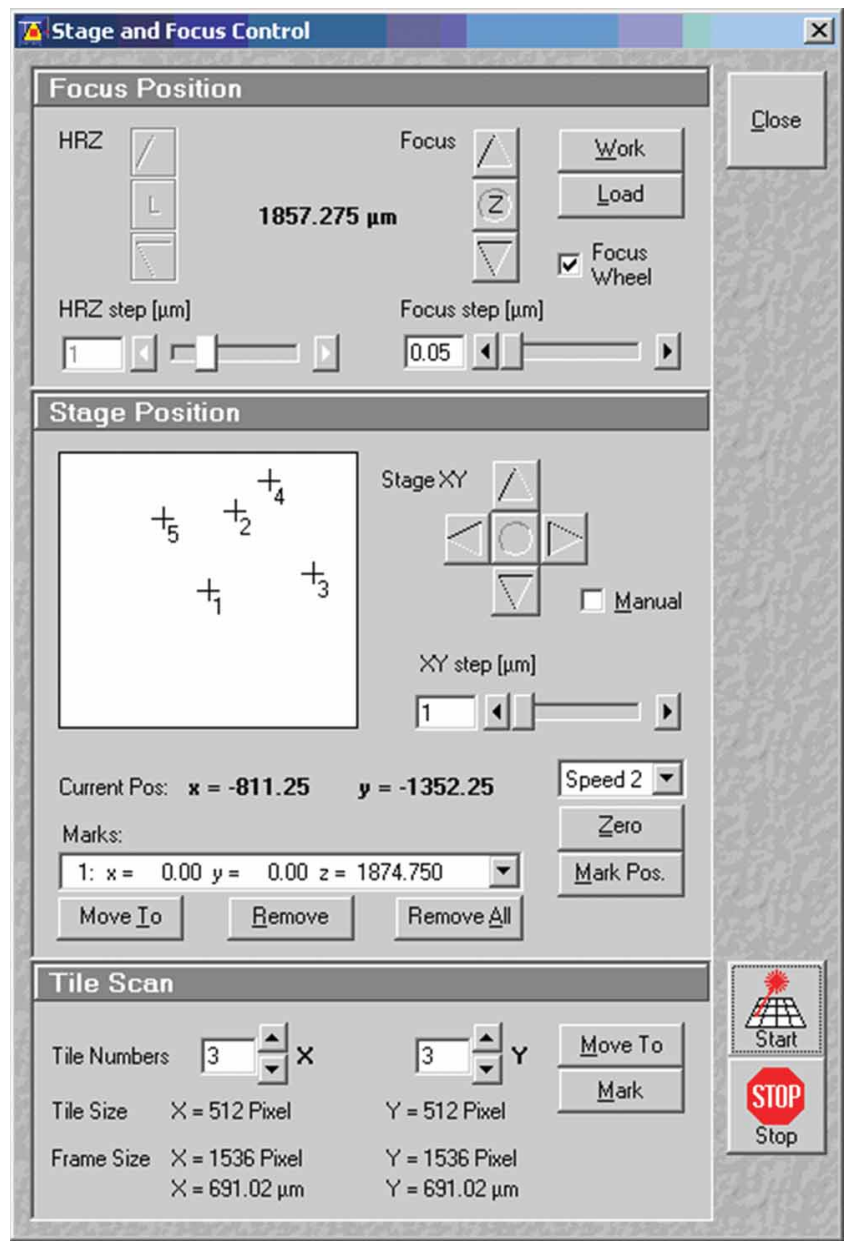

Figure 3 | Screenshot of the Tile Scan window of the LSM510 software. Five nonoverlapping fields are selected in the Stage Position dialog. A $3 \times 3$ tile is selected in the Tile Scan dialog.

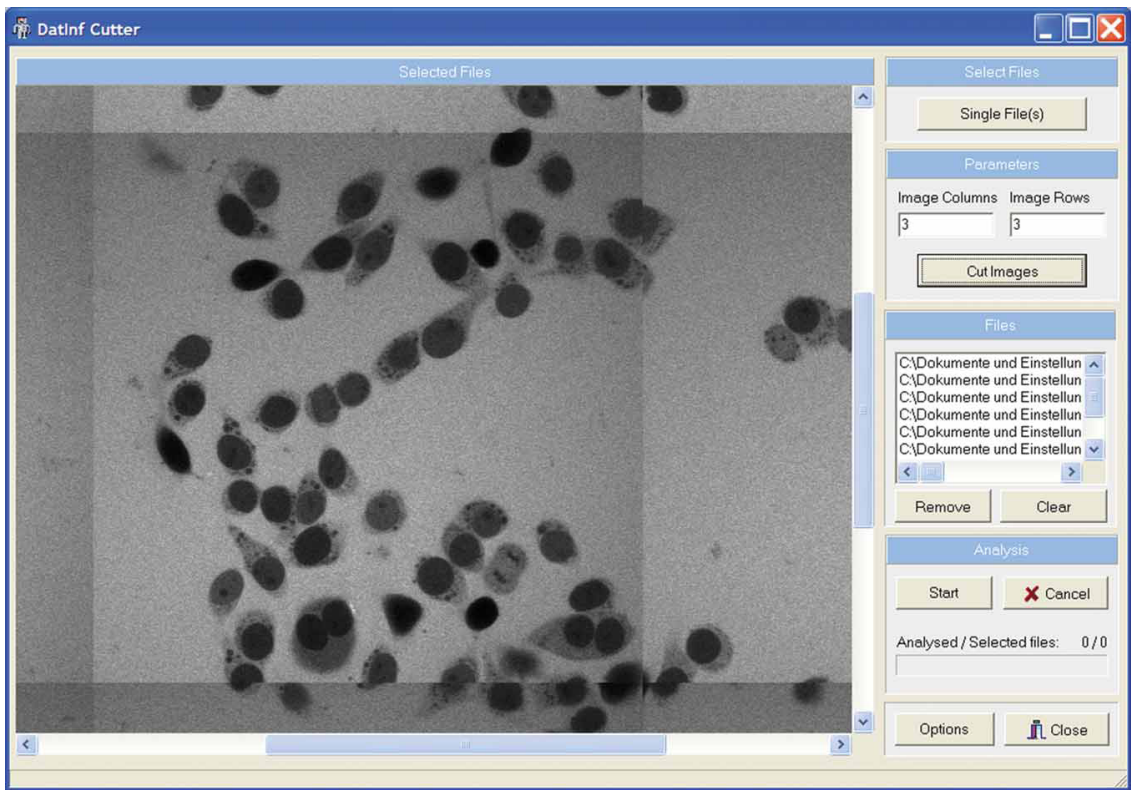

Figure 4 | Screenshot of Cutter. After loading a tiled image using the Select Files button and decomposing it with Cut Images, the single images are listed in the dialog Files. the experimental conditions, image characteristics may vary with respect to brightness, signal/background ratio and shape of the nuclei. This can be accounted for by changing the values of the three parameters in the NPA.ini file: "plasma," "nuclei" and "form." A detailed procedure for finding and validating optimal settings can be found in ref. 15.

\section{- TIMING}

Step 1: approximately $48 \mathrm{~h}$

Steps 2-5: 90-120 min

Steps 6-10: $25 \mathrm{~min}$

Steps 11-13: $10 \mathrm{~min}$

Steps 14-16: 75 min

Step 17: $120 \mathrm{~min}$

Step 18: $30 \mathrm{~min}$

Steps 19-23: 30 min

Step 24-30: $25 \mathrm{~min}$ 
Step 31: depending on the number of images, approximately 30 min per coverslip when you analyze five different $3 \times 3$ tile scan images.

To increase the throughput, two people may work in parallel: the first one prepares the specimen (Steps 24-29), and the second operates the microscope (Step 30) (see Fig. 5).

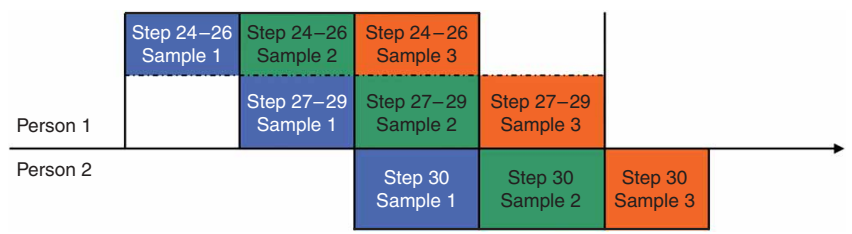

? TROUBLESHOOTING

Figure 5 | Timing of Steps 2430 for parallel sample processing.

Troubleshooting advice can be found in Table 1.

TABLE 1 | Troubleshooting table.

\begin{tabular}{|c|c|c|}
\hline Problem & Possible reason & Solution \\
\hline \multirow[t]{3}{*}{ Cells are not permeabilized } & $\begin{array}{l}\text { Incubation time is too short } \\
\text { (Step 20) }\end{array}$ & Increase incubation time in steps of $30 \mathrm{~s}$ \\
\hline & $\begin{array}{l}\text { Cell density is too high } \\
\text { (Step 18) }\end{array}$ & $\begin{array}{l}\text { Digitonin is a cholesterol analog that incorporates into } \\
\text { membranes. If the number of cells is too high the } \\
\text { amount of digitonin may not be sufficient to permea- } \\
\text { bilize all cells. Seed cells at a lower density }\end{array}$ \\
\hline & $\begin{array}{l}\text { Digitonin concentration is too low } \\
\text { (Step 20) }\end{array}$ & $\begin{array}{l}\text { Increase digitonin concentration. The concentration } \\
\text { indicated here }\left(24 \mathrm{~g} \mathrm{~m}^{-1}\right) \text { works for batch permea- } \\
\text { bilizations in glass beakers }\end{array}$ \\
\hline
\end{tabular}

Nuclei are permeabilized in the controls

Strongly fluorescent speckles in the cytoplasm

No significant change in nuclear permeability is observed
Incubation time is too long

(Step 20)

Cell density is too low

(Step 18)

Digitonin concentration is too high

(Step 20)

Permeabilized cells are too old

(Step 23)

Possibly owing to bad batches of digitonin

The extract does not contain a permeabilizing activity

The nuclear signal is too high in the control

The settings of the NPA software are not properly adjusted
See above

See above

See above

Permeabilized cells are stable up to at most $90 \mathrm{~min}$ in TRB on ice

Purity of digitonin is critical. Change digitonin batch. Use the minimum necessary concentration

Choose other extracts or be happy with the result. As a positive control you can add $1-5 \mu \mathrm{M} \mathrm{Ca}^{2+}$ to your extract. This leads to a substantial increase in nuclear envelope permeability

Isolate the S-20 extracts used for control incubations from a healthy culture; minimize the time of the isolation procedure

Optimize the settings as described in Roehrig et al. ${ }^{15}$

\section{ANTICIPATED RESULTS}

\section{Isolation of S-20 extracts}

This protocol typically yields $7-10 \mathrm{mg}$ of S-20 extracts when starting from a logarithmic culture (density of Jurkat cells approximately $4-5 \times 10^{5}$ cells per $\mathrm{ml}, 4 \times 10^{8}$ cells). This suffices to perform 50 incubations. Enough extract should be
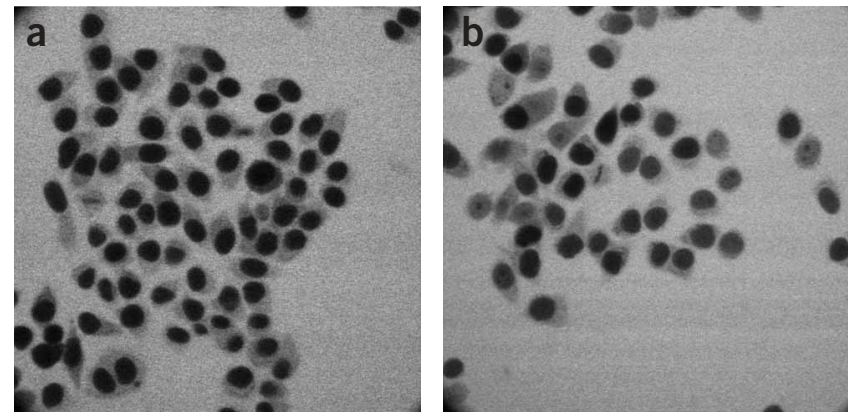

Figure 6 | Confocal images of HeLa cells treated with (a) control or (b) apoptotic S 20 extract from Jurkat T cells. prepared to perform a complete series of experiments. This minimizes variations as a result of changing extract batches. When extracts from apoptotic cells are used, it is recommended that you employ lysates containing comparable amounts of active caspases. Caspase activity assays are commercially available (e.g., Fluorimetric Caspase Assay).

\section{Preparation of permeabilized cells, preparation of microscopy specimen and image acquisition}

The cells should be at $30-40 \%$ confluence. If the permeabilization conditions are appropriate and the S-20 extract is derived from untreated, healthy cells, the nuclei 
should appear in the laser scanning microscope as dark circles (Fig. 6a). Incubation with extracts from cells triggered to undergo apoptosis results in the appearance of bright nuclei (see Fig. 6b).

The quality of the results critically depends on exact timing, in particular during the permeabilization step (Step 20), the treatment with S-20 extract (Step 26) and confocal microscopy (Step 30). Handling the coverslips and operating the microscope require training. We therefore recommend practicing the protocol with an experienced microscopist before starting large experiment series.

\section{Image data analysis}

Figure 7 shows typical results obtained with three different cell lines. Each bar represents the average intensity value obtained from 70 to 120 images for a total of approximately 1,000 evaluated nuclei. The nuclear fluorescence signal is normalized to the control. The difference in intensity is regarded as significant only if the $P$-value determined by a two-tailed $t$-test is less than 0.01 (confidence level at least $99 \%$ ).

In all three experiments, incubation with S-20 extracts from CH11-treated Jurkat T-cells leads to a significant increase in nuclear envelope permeability $(P<0.001)$.

ACKNOWLEDGMENTS We thank Marijke Baldock for technical assistance and DatInf $\mathrm{GmbH}$ for software development. This work is supported by a grant from the Deutsche Forschungsgemeinschaft to E.F. M. (MA 2385/4).

COMPETING INTERESTS STATEMENT The authors declare that they have no competing financial interests.

Published online at http://www.natureprotocols.com

Reprints and permissions information is available online at http://npg.nature.com/ reprintsandpermissions

1. Fried, H. \& Kutay, U. Nucleocytoplasmic transport: taking an inventory. Cell Mol. Life Sci. 60, 16591688 (2003).

2. Tran, E.J. \& Wente, S.R. Dynamic nuclear pore complexes: life on the edge. Cell 125, 10411053 (2006).

3. Ferrando May, E. Nucleocytoplasmic transport in apoptosis. Cell Death Differ. 12, 12631276 (2005)

4. Kodiha, M., Chu, A., Matusiewicz, N. \& Stochaj, U. Multiple mechanisms promote the inhibition of classical nuclear import upon exposure to severe oxidative stress. Cell Death Differ. 11, 862874 (2004).

5. Faleiro, L. \& Lazebnik, Y. Caspases disrupt the nuclear cytoplasmic barrier. J. Cell Biol. 151, 951959 (2000).

6. Patre, M. et al. Caspases target only two architectural components within the core structure of the nuclear pore complex. J. Biol. Chem. 281, 12961304 (2006).
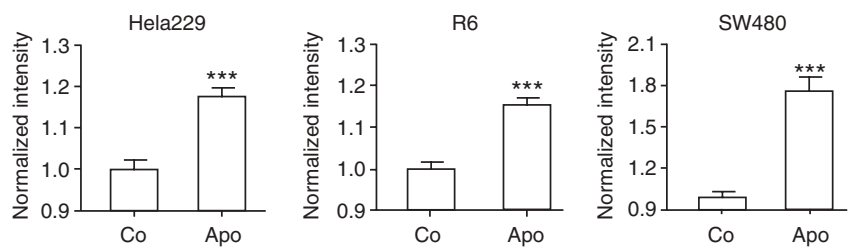

Figure 7 | Increase of nuclear envelope permeability in semi permeabilized cells incubated with S 20 extracts from apoptotic Jurkat T cells. The results were analyzed with a two tailed $t$ test. ${ }^{* *} P<<0.001$.
7. Belov, G.A. et al. Bidirectional increase in permeability of nuclear envelope upon poliovirus infection and accompanying alterations of nuclear pores. J. Virol. 78 1016610177 (2004).

8. Makhnevych, T., Lusk, C.P., Anderson, A.M., Aitchison, J.D. \& Wozniak, R.W. Cell cycle regulated transport controlled by alterations in the nuclear pore complex. Cell 115, 813823 (2003).

9. Jiang, L.W. \& Schindler, M. Nuclear transport in $3 T 3$ fibroblasts: effects of growth factors, transformation, and cell shape. J. Cell Biol. 106, 1319 (1988).

10. Feldherr, C.M. \& Akin, D. Regulation of nuclear transport in proliferating and quiescent cells. Exp. Cell Res. 205, 179186 (1993).

11. Adam, S.A., Marr, R.S. \& Gerace, L. Nuclear protein import in permeabilized mammalian cells requires soluble cytoplasmic factors. J. Cell Biol. 111, 807816 (1990).

12. Ribbeck, K. \& Gorlich, D. Kinetic analysis of translocation through nuclear pore complexes. EMBO J. 20, 13201330 (2001).

13. Ribbeck, K. \& Gorlich, D. The permeability barrier of nuclear pore complexes appears to operate via hydrophobic exclusion. EMBO J. 21, 26642671 (2002).

14. Ferrando May, E. et al. Caspases mediate nucleoporin cleavage, but not early redistribution of nuclear transport factors and modulation of nuclear permeability in apoptosis. Cell Death Differ. 8, 495505 (2001).

15. Roehrig, S., Tabbert, A. \& Ferrando May, E. In vitro measurement of nuclear permeability changes in apoptosis. Anal. Biochem. 318, 244253 (2003).

16. Lenart, P. \& Ellenberg, J. Monitoring the permeability of the nuclear envelope during the cell cycle. Methods 38, 1724 (2006). 